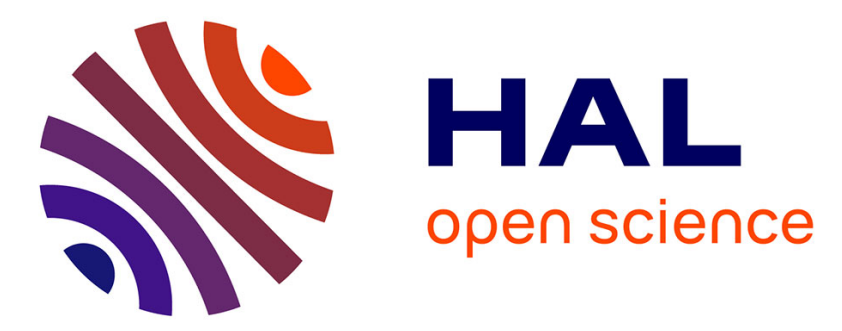

\title{
Chalcogen bonding interactions in organic selenocyanates From cooperativity to chelation
}

O. Jeannin, H.-T. Huynh, A.M.S. Riel, M. Fourmigué

\section{To cite this version:}

O. Jeannin, H.-T. Huynh, A.M.S. Riel, M. Fourmigué. Chalcogen bonding interactions in organic selenocyanates From cooperativity to chelation. New Journal of Chemistry, 2018, 42 (13), pp.1050210509. 10.1039/c8nj00554k . hal-01835065

HAL Id: hal-01835065

https://hal-univ-rennes1.archives-ouvertes.fr/hal-01835065

Submitted on 13 Jul 2018

HAL is a multi-disciplinary open access archive for the deposit and dissemination of scientific research documents, whether they are published or not. The documents may come from teaching and research institutions in France or abroad, or from public or private research centers.
L'archive ouverte pluridisciplinaire HAL, est destinée au dépôt et à la diffusion de documents scientifiques de niveau recherche, publiés ou non, émanant des établissements d'enseignement et de recherche français ou étrangers, des laboratoires publics ou privés. 


\title{
Chalcogen bonding interactions in organic selenocyanates: from cooperativity to chelation $\dagger$
}

Olivier Jeannin, ${ }^{a}$ Huu-Tri Huynh, ${ }^{a}$ Asia Marie S. Riel, ${ }^{a, b}$ and Marc Fourmiguée ${ }^{\star a}$

a Univ Rennes, CNRS, ISCR (Institut des Sciences Chimiques de Rennes) - UMR 6226, 35000 Rennes (France)

b Department of Chemistry, University of Montana, 32 Campus Dr., Missoula, USA

\begin{abstract}
Intermolecular chalcogen bonding interactions are identified in crystalline organic selenocyanates where a linear Se $\cdots \cdot \mathrm{N} \equiv \mathrm{C}$ interaction takes place, leading to the recurrent formation of chain-like motifs $\cdots \mathrm{Se}(\mathrm{R})-\mathrm{CN} \cdots \mathrm{Se}(\mathrm{R})-\mathrm{CN} \cdots$, stabilized by cooperativity. Analysis of 15 reported structures of such selenocyanates is complemented by the structural determinations of three other novel polytopic selenocyanates, namely 1,3,5-tris(selenocyanatomethyl)benzene (1a), 1,3,5tris(selenocyanatomethyl)-2,4,6-trimethylbenzene (1) and 1,2,4,5-tetrakis(seleno cyanatomethyl)benzene (2). While the recurrent chain-like motifs with short and linear Se $\cdots \mathrm{N}$ contacts are indeed observed in the pure compounds, solvates with DMF and AcOEt also demonstrate that the nitrile $\mathrm{N}$ atom can be easily displaced from the chalcogen bond by stronger Lewis bases such as carbonyl oxygen atoms, leading in the case of (2)•(DMF) 2 to a chelating motif where two neighboring $\mathrm{CH}_{2}-\mathrm{SeCN}$ groups link to the same oxygen atom through Se...O interactions.
\end{abstract}

† CCDC 1820888-1820893. For crystallographic data in CIF format see DOI: 10.1039/XXXXXXX 


\section{Introduction}

The rediscovery of halogen bonding (XB) interactions in the last twenty years ${ }^{1}$ has recently evolved toward the identification of similar properties in the chalcogen, pnictogen or even tetrel series. ${ }^{2,3}$ Recent illustrations of chalcogen bonding are found for example in the solid state structures of benzo-2,1,3-selenadiazoles, ${ }^{4}$ benzo-1,3-tellurazoles, ${ }^{5}$ iso-tellurazole N-oxides, ${ }^{6}$ or selenophtalic anhydride, ${ }^{7}$ as well as in the use of chelating bis-tellurophene ${ }^{8}$ or bis(benzimidazolium-selenomethyl) derivatives ${ }^{9}$ in catalytic reactions. One striking difference with the halogen bond donors is the distribution of the electrostatic surface potential. While one single charge-depleted area, the $\sigma$-hole, is identified in the prolongation of the covalent $\mathrm{C}-$ Hal bond, theoretical and experimental investigations of molecules with activated chalcogen atoms have unambiguously demonstrated the presence of two such charge-depleted area, each of them in the prolongation of the two carbon-chalcogen bonds. ${ }^{2,3,10}$ The simplest and most convincing example was already identified years ago in $\mathrm{Se}(\mathrm{CN})_{2},{ }^{11}$ and revisited recently. ${ }^{12}$ Its X-ray crystal structure (Fig. 1a) shows indeed two nitrogen atoms of neighboring molecules pointing toward the $\sigma$-holes of the selenium atom, with Se $\bullet \cdot \mathrm{N}$ intermolecular distances, 2.813(9) and 2.835(7) $\AA$, well below the sum of the van der Waals radii (3.45 $\AA$ ), and C-Se•••N angles close to linearity $\left(166-170^{\circ}\right)$. Cocrystallization of $\operatorname{Se}(\mathrm{CN})_{2}$ with 18 -crown-6 is also reported to afford a co-crystal (Fig. 1b), ${ }^{13}$ where again the two $\sigma$-holes of the selenium atoms are clearly interacting with two oxygen atoms of the 18-crown-6 in a 1:1 adduct. Selenophtalic anhydride provides another example where both charge-depleted area were identified from an experimental high resolution X-ray data collection. ${ }^{7}$

(a)

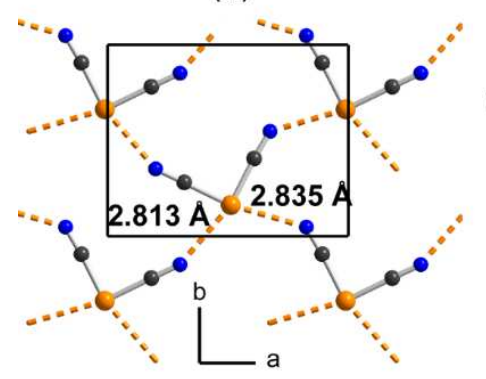

(b)

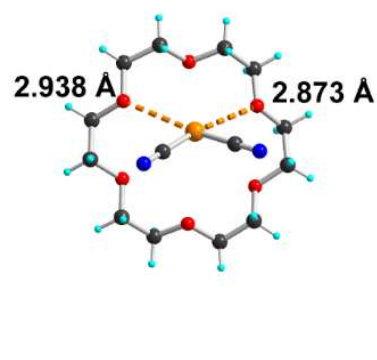

Fig. 1 Detail of the solid state structure of (a) $\mathrm{Se}(\mathrm{CN})_{2}$, and (b) $\mathrm{Se}(\mathrm{CN})_{2} \cdot(18$-crown-6) adduct in $\mathrm{Se}(\mathrm{CN})_{2} \cdot(18 \text {-crown-6) })_{1.5}$. Chalcogen bond interactions are indicated as orange dotted lines. 
Considering that the predictability of halogen bonding in crystal engineering strategies is essentially due to the presence of one single $\sigma$-hole in the prolongation of the $\mathrm{C}-\mathrm{X}$ bond, we postulated that the ability of chalcogen atoms to provide a similar predictability despite the presence of two $\sigma$-holes can be strongly enhanced if one is able to favor one $\sigma$-hole over the other. For that purpose, the use of unsymmetrically substituted chalcogen atoms, with one electron-withdrawing (EWG) group and one electron-releasing (ERG) group should favor the presence of a stronger $\sigma$-hole in the prolongation of the EWG-Se bond. ${ }^{9}$ Based on this assumption, organic selenocyanates appear as ideal candidates, as the selenium atom is simultaneously linked to the strongly electron-withdrawing nitrile substituent and to a more electron-releasing alkyl, benzyl or aryl group. Following earlier conclusions by Bauza et al., ${ }^{3 \mathrm{a}}$ investigations of the crystal structures of organic selenocyanates reported in $\mathrm{CSD}^{14}$ confirmed this assumption, as detailed below. We also recently showed that molecules bearing two such selenocyanate moieties, ${ }^{15}$ as the ortho-, meta- and para- bis(selenocyanato)xylene (Chart 1) are indeed able to act as ditopic chalcogen bond donors when faced with ditopic Lewis bases such as 4,4'-bipyridine to afford one-dimensional structures. We want here to extend this pool of benzylic selenocyanates to the tris and tetrakis-substituted derivatives (Chart 1), as described in a second part below, where their preparation and solid state structures will be reported and analyzed.

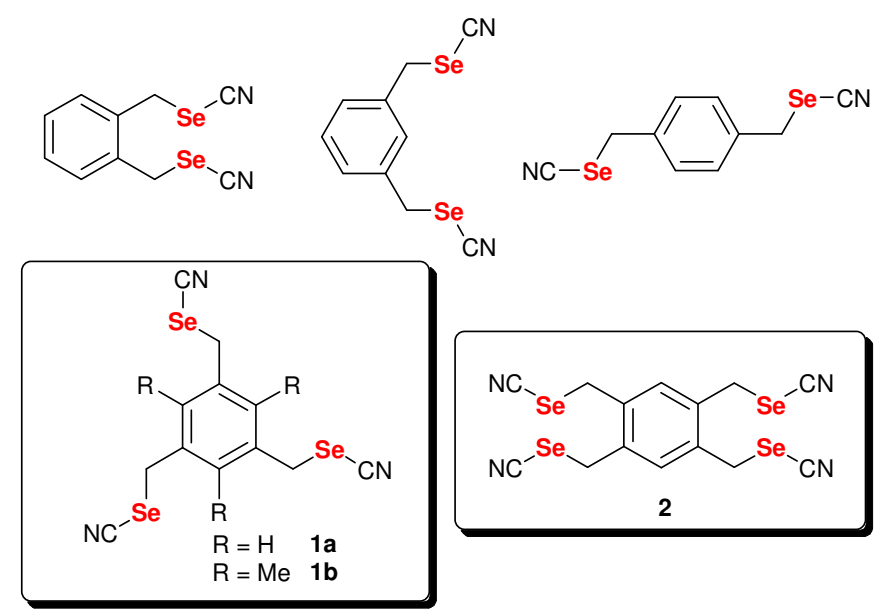

Chart 1 Reported (top) and novel (1a, 1b, 2) benzylic selenocyanates 


\section{Results}

\section{Analysis of reported solid state structures of organic selenocyanates}

Most of the organic selenocyanates found in CSD show evidence of a chalcogen bonding interaction involving the selenium atom as chalcogen bond donor. In the following, we will described successively: (i) systems with intramolecular chalcogen bond, (ii) aromatic selenocyanates, (iii) benzylic and allylic selenocyanates, (iv) aliphatic selenocyanates. In the following, the evaluation of the strength of the chalcogen bond in all these systems will be based primarily on the reduction ration of the actual Se••Y distance, relative to the sum of the van der Waals radii of the interacting atoms, with Se: $1.90 \AA, \mathrm{N}: 1.55 \AA$, O: $1.52 \AA$, that is $\mathrm{d}_{\mathrm{vdw}}(\mathrm{Se} \bullet \bullet N)=3.45 \AA, \mathrm{d}_{\mathrm{vdW}}(\mathrm{Se} \bullet \bullet \cdot \mathrm{O})=3.42 \AA, \mathrm{d}_{\mathrm{vdw}}(\mathrm{Se} \bullet \bullet \cdot \mathrm{Se})=3.80 \AA$.

Intramolecular chalcogen bonding is found in three examples (Fig. 2), namely methyl 2-selenocyanatobenzoate, ${ }^{16}$ phenacyl selenocyanate ${ }^{17}$ and 8-(dimethylamino)-1-naphthyl selenocyanate. ${ }^{18}$ The planarity of the three systems despite the strong steric constraints demonstrates the stabilization brought by the chalcogen bond interaction. The chalcogen bond distances are accordingly very short, with reduction ratio down to 0.72 . The interaction takes place in the prolongation of the $\mathrm{Se}-\mathrm{CN}$ bond, demonstrating also the selective activation of one $\sigma$-hole site on the selenium atom by the opposite nitrile group. It already confirms the interest of organic selenocyanates derivatives to activate one single strong $\sigma$-hole on the selenium atom.

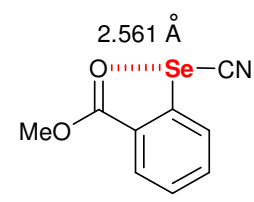

AHEQIN $\mathrm{RR}=0.749$

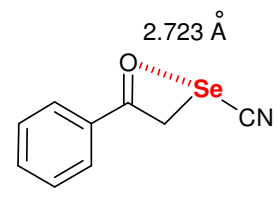

FAGGAV $\mathrm{RR}=0.796$

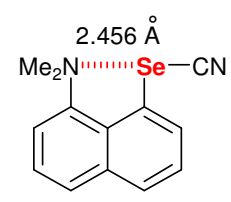

GIYJUV

$\mathrm{RR}=0.712$

Fig. 2 Details on intramolecular chalcogen bond interactions in three reported examples (with CCDC REFCODE) 
Table 1 Details of the structural characteristics of the chalcogen bond interactions in reported compounds. RR stands for reduction ratio and is given by the ratio of the observed interatomic distance over the sum of the van der Waals radii of interacting atoms.

\begin{tabular}{|c|c|c|c|c|c|}
\hline Compound & REFCODE & $\begin{array}{l}\mathrm{Se} \bullet \bullet N(\mathrm{O}, \mathrm{Se}) \\
(\AA)\end{array}$ & $\mathrm{RR}$ & $\begin{array}{l}\mathrm{C}-\mathrm{Se} \bullet \bullet \mathrm{Y} \\
\left({ }^{\circ}\right)\end{array}$ & $\overline{R e f}$ \\
\hline \multirow[t]{2}{*}{$\mathrm{Se}(\mathrm{CN})_{2}$} & UQAXUH & $2.813(9)$ & 0.815 & $166.3(2)$ & 12 \\
\hline & & $2.835(7)$ & 0.822 & $170.4(2)$ & \\
\hline \multirow[t]{2}{*}{$\mathrm{Se}(\mathrm{CN})_{2} \bullet 1.5(18$-crown-6) } & QUHYAV & $2.873(2)(\mathrm{O})$ & 0.840 & $167.2(1)$ & 13 \\
\hline & & $2.938(10)(\mathrm{O})$ & 0.856 & 161.2(1) & \\
\hline \multicolumn{6}{|l|}{ Intramolecular: } \\
\hline Methyl & AHEQUIN & $2.561(1)(\mathrm{O})$ & 0.749 & $170.34(6)$ & 16 \\
\hline \multicolumn{6}{|l|}{ 2-selenocyanatobenzoate } \\
\hline phenacyl selenocyanate & FAGGAV & $2.723(6)(\mathrm{O})$ & 0.796 & $152.0(1)$ & 17 \\
\hline \multicolumn{6}{|l|}{$\begin{array}{l}\left.\text { 8-( } \mathrm{NMe}_{2}\right)-1 \text {-naphthyl } \\
\text { selenocyanate }\end{array}$} \\
\hline \multicolumn{6}{|l|}{ Aromatic selenocyanates: } \\
\hline \multirow[t]{2}{*}{$\mathrm{PhSeCN}$} & CIBFUP & $3.023(3)^{(\mathrm{a})}$ & 0.876 & $172.9(1)$ & 19 \\
\hline & & $3.065(4)$ & 0.888 & $166.1(1)$ & \\
\hline$p-(\mathrm{SeCN})_{2} \mathrm{C}_{6} \mathrm{H}_{4}$ & SECNBZ & $3.06(2)$ & 0.887 & $162.32(8)$ & 21 \\
\hline \multirow[t]{2}{*}{$\mathrm{C}_{6} \mathrm{~F}_{5} \mathrm{SeCN}$} & BATDIJ & $2.958(10)^{(a)}$ & 0.857 & $175.6(8)$ & 20 \\
\hline & & $2.964(9)$ & 0.859 & $172.1(4)$ & \\
\hline \multirow[t]{2}{*}{$\mathrm{C}_{6} \mathrm{H}_{2}\left(\mathrm{CF}_{3}\right)_{3} \mathrm{SeCN}$} & KABTEN & $2.883(6)^{(b)}$ & 0.836 & $173.1(2)$ & 22 \\
\hline & & $2.968(5)$ & 0.860 & $166.4(2)$ & \\
\hline 3-(SeCN)pyridine & WERYAT & $2.843(10)$ & 0.824 & $174.0(2)$ & 24 \\
\hline \multicolumn{6}{|l|}{ Benzylic selenocyanates: } \\
\hline Benzylselenocyanate & CIGGOO & $2.997(18)$ & 0.869 & 167.1 & 25 \\
\hline \multirow[t]{2}{*}{ ortho-bis(SeCN)xylene } & NARBIR & $2.985(8)$ & 0.865 & $172.9(3)$ & 26 \\
\hline & & $2.969(9)$ & 0.860 & $172.6(3)$ & \\
\hline \multirow[t]{4}{*}{ meta-bis(SeCN)xylene } & & $2.965(24)^{(a)}$ & 0.859 & $175.9(7)$ & 15 \\
\hline & & $3.017(24)$ & 0.874 & $175.7(7)$ & \\
\hline & & $3.010(24)$ & 0.872 & $172.9(7)$ & \\
\hline & & $3.015(24)$ & 0.874 & $174.1(7)$ & \\
\hline \multirow[t]{2}{*}{ para-bis(SeCN)xylene } & POXYEH & $2.997(18)^{(a)}$ & 0.860 & $174.4(8)$ & 27 \\
\hline & & $3.022(18)$ & 0.876 & $171.8(5)$ & \\
\hline \multirow[t]{2}{*}{ 4-nitrobenzyl-selenocyanate } & CIGGEE & $3.005(7)(\mathrm{O})$ & 0.879 & 166.2 & 25 \\
\hline & & $3.174(9)(\mathrm{O})$ & 0.928 & 163.9 & \\
\hline 2-(MeSe)benzylselenocyanate & YUNSIK & $3.467(1)(\mathrm{Se})$ & 0.912 & $163.4(1)$ & 28 \\
\hline \multicolumn{6}{|l|}{ Aliphatic selenocyanates: } \\
\hline $\begin{array}{l}\text { 1,1-bis(selenocyanatoethyl) } \\
\text { cyclohexane }\end{array}$ & GOHMEW & $3.199(2)$ & 0.927 & $145.7(8)$ & 29 \\
\hline Cholesterol derivative & ZUTTAL & $3.36(2)$ & 0.974 & $157.9(7)$ & 30 \\
\hline
\end{tabular}


Aromatic selenocyanates represent the largest reported group, with an interesting series provided by phenyl selenocyanate, ${ }^{19}$ pentafluorophenyl selenocyanate, ${ }^{20}$ 1,4bis(selenocyanato)benzene ${ }^{21}$ and 2,4,6-tris(trifluoromethyl)phenyl selenocyanate. ${ }^{22}$ As shown in Fig. 3, a linear Se•••N interaction involving the nitrogen atom of the $\mathrm{C} \equiv \mathrm{N}$ group takes place, leading to the recurrent formation of chain-like motifs $\bullet \bullet S \mathrm{Se}(\mathrm{R})-\mathrm{CN} \bullet \bullet \mathrm{Se}(\mathrm{R})-\mathrm{CN} \bullet \bullet$. We also observe a strengthening of the interaction with the most-electron-withdrawing aromatic cores, most probably attributable to an enhancement of the $\sigma$-hole on the selenium atom. We believe that such one-dimensional systems are also stabilized by cooperativity, as indeed theoretically demonstrated in model systems. ${ }^{23}$ Structural characteristics are gathered in Table 1. A similar Se••N interaction is also observed in 1,4-bis(selenocyanato)benzene (CSD : SECNBZ) where it develops in two dimensions.

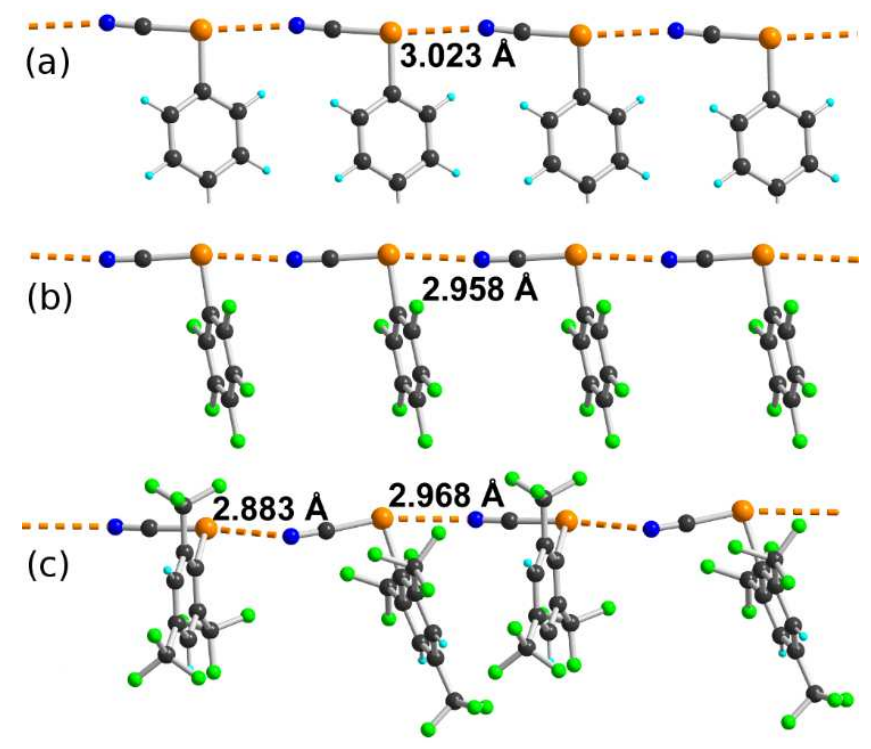

Fig. 3 The chain-like structures formed by chalcogen bonding in (a) phenyl selenocyanate, (b) pentafluorophenyl selenocyanate, and (c) 2,4,6-tris(trifluoromethyl)phenyl selenocyanate.

Another interesting example are provided 3-selenocyanatopyridine ${ }^{24}$ (Fig. 4) where the pyridinyl nitrogen atom is now engaged in the chalcogen bond, with a short $\mathrm{Se} \bullet \bullet \mathrm{N}_{\text {Py }}$ distance $(\mathrm{RR}=0.824)$, demonstrating that the nitrile $\mathrm{N}$ atom can be easily displaced from the chalcogen bond by stronger Lewis bases, as already illustrated above in the Introduction with the adduct of $\mathrm{Se}(\mathrm{CN})_{2}$ with 16-crown-6 (Fig. 1b). 


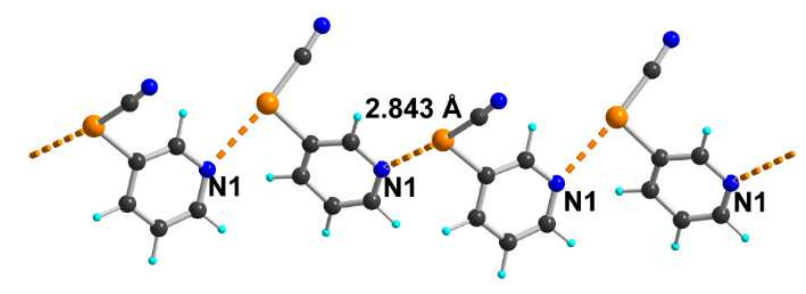

Fig. 4 Chalcogen bonding in 3-selenocyanatopyridine

Benzylic selenocyanates are easily prepared from benzyl halide and potassium selenocyanates. Many examples were therefore reported and some of them were structurally characterized. Benzylselenocyanate ${ }^{25}$ itself and the three ortho- ${ }^{26}$ meta- $^{15}$ and parabis(selenocyanatato)xylene ${ }^{27}$ have been reported. As shown in Fig. 5, they all exhibit the recurrent $\bullet \bullet \cdot \mathrm{Se}(\mathrm{R})-\mathrm{CN} \bullet \bullet \mathrm{Se}(\mathrm{R})-\mathrm{CN} \bullet \bullet$ chain-like motif. The Se•••N intermolecular distances are comparable to those reported above in aromatic selenocyanates.

(a)
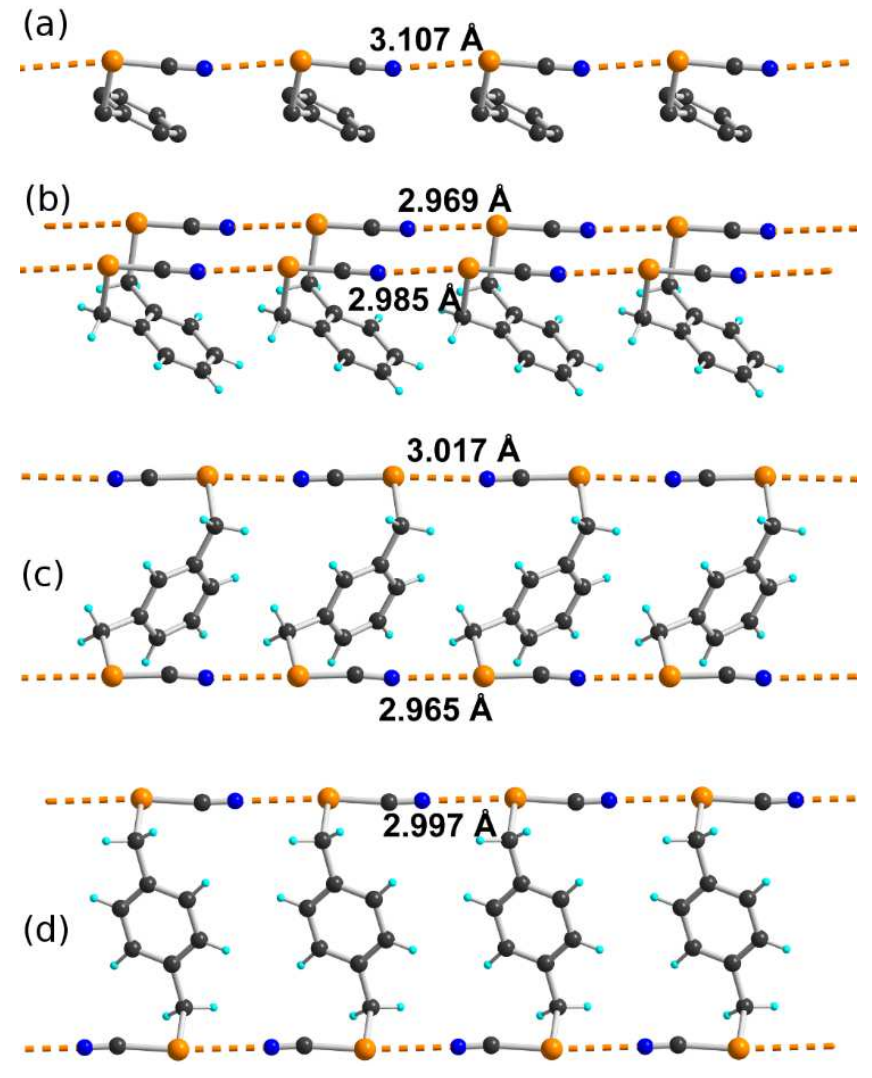

Fig. 5 Recurrent $\cdots \cdot \mathrm{Se}(\mathrm{R})-\mathrm{CN} \cdots \cdot \mathrm{Se}(\mathrm{R})-\mathrm{CN} \cdots \cdot$ chain-like motif in benzylic selenocyanates such as (a) benzylselenocyanate (hydrogen atoms were omitted), (b) ortho-bis(selenocyanatato)xylene, (c) metabis(selenocyanatato)xylene, and (d) para-bis(selenocyanatato)xylene 
The robustness of these chains is however questioned when a stronger chalcogen bond acceptor is present. This is indeed the case in 4-nitrobenzyl-selenocyanate ${ }^{25}$ and 2(methylselanyl)benzyl selenocyanate ${ }^{28}$ where either oxygen atoms from a $-\mathrm{NO}_{2}$ group or selenium atom of a-SeMe group act as chalcogen bond acceptors (Fig. 6). The structure of 4nitrobenzyl-selenocyanate is particularly interesting (Fig 6a) as it demonstrates that the two $\sigma$ holes on the selenium atom are here involved in a chalcogen bonding interaction. The strongest one, at $180^{\circ}$ from the $\mathrm{CN}$ group gives rise to the shortest Se•••O contact (3.005 $\AA$ ), while a weaker one, at $180^{\circ}$ from the para-nitrobenzyl group, gives a Se•••O distance at $3.174 \AA$, notably shorter than the sum of the van der Waals radii (3.42 $\AA$ )

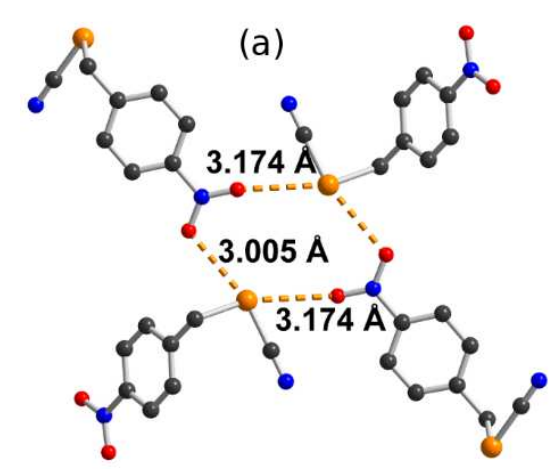

(b)

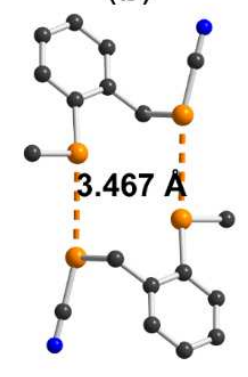

Fig. 6 Detail of the supramolecular motifs developed by (a) 4-nitrobenzyl-selenocyanate, and (b) 2(methylselanyl)benzyl selenocyanate (Hydrogen atoms were omitted).

Two examples involving aliphatic selenocyanates involve 1,1-bis(selenocyanatoethyl) cyclohexane ${ }^{29}$ (CSD: GIHMEW) and a cholesterol derivative (CSD: ZUTTAL) ${ }^{30}$ They also exhibit this chain motif but with rather weaker interactions (Table 1).

\section{Novel tris- and tetrakis organic selenocyanates: a recurrent chain motif}

Following our preliminary experiments aimed at unravel the ability of bis(selenocyanates) derivatives such as the three ortho-,${ }^{26}$ meta-,${ }^{15}$ and para- bis(selenocyanatato)xylene ${ }^{27}$ to form one-dimensional structures upon co-crystallization with neutral ditopic Lewis bases $(4,4$ 'bipyridine), we turned our attention to the corresponding tris- and tetrakis-substituted derivatives, namely 1,3,5-tris(selenocyanatomethyl)benzene (1a), 1,3,5-tris(selenocyanato methyl)-2,4,6-trimethylbenzene (1b) and 1,2,4,5-tetrakis(selenocyanatomethyl)benzene (2). We describe in the following their synthesis and analyze in details their crystal structures, where the chain-like motif $\bullet \bullet \mathrm{Se}(\mathrm{R})-\mathrm{CN} \bullet \bullet \mathrm{Se}(\mathrm{R})-\mathrm{CN} \bullet \bullet$ mentioned above is also acting as a powerful supramolecular motif. 
Both 1a, $\mathbf{1 b}$ and $\mathbf{2}$ were prepared from the reaction of the corresponding tris(bromomethyl) and tetrakis-(bromomethyl)benzene derivatives with $\mathrm{KSeCN}$ (see Exp. Section). In the presence of AcOEt or DMF, $\mathbf{1 b}$ and $\mathbf{2}$ also crystallize as solvates, formulated as $\mathbf{1 b} \cdot \mathrm{AcOEt}, \mathbf{1 b} \cdot \mathrm{DMF}$ and $\mathbf{2} \bullet(\mathrm{DMF})_{2}$. We will first describe the crystal structures of $\mathbf{1 a}, \mathbf{1 b}$, $\mathbf{1 b} \cdot \mathrm{DMF}$ and $\mathbf{2}$ where only Se••NC interactions are found, while the structures of $\mathbf{1 b} \bullet \mathrm{AcOEt}$ and $2 \bullet(D M F)_{2}$ will be described in a second part, as they also involve Se••O chelating interactions with the solvent molecules (see below).

1a crystallizes in the monoclinic system, space group $\mathrm{P} 21 / \mathrm{n}, \mathbf{1 b}$ in the monoclinic system, space group $\mathrm{C} 2 / \mathrm{c}$, and $\mathbf{1 b} \cdot \mathrm{DMF}$ in the triclinic system, space group $\mathrm{P}-1$ with in the three structures one molecule in general position. On the other hand, tetra-substituted compound 2 crystallizes on an inversion center, in the monoclinic P2 $2 /$ c space group. As shown in Fig. 7ac, in the tritopic derivatives $\mathbf{1 a}$ and $\mathbf{1 b}$, we find two $\mathrm{SeCN}$ groups above the benzene ring with one below. A similar geometry for $\mathbf{1 b}$ is found in its DMF solvate (Fig 7d). Note also the positional disorder of one selenocyanate group in 1b, with a 29:71 distribution for Se31 and Se32.
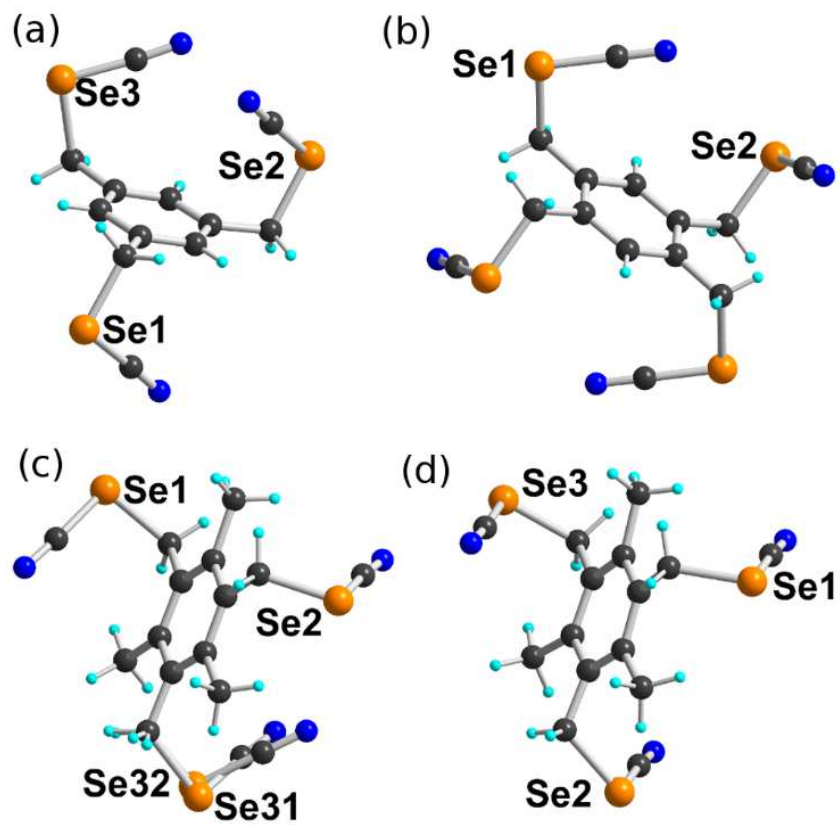

Fig. 7 Molecular structures of (a) 1a, (b) 2, (c) $\mathbf{1 b}$ and (d) $\mathbf{1 b}$ in $\mathbf{1 b} \cdot(\mathrm{DMF})$.

The solid state organization of 1a (Fig. 8) is characterized by the occurrence of two strong Se $\bullet \cdot N$ chalcogen bonds (see Table 2) leading to the formation of infinite chains $\bullet \bullet S e 1-$ $\mathrm{C} 1 \equiv \mathrm{N} 1 \bullet \bullet \mathrm{Se} 1-\mathrm{C} 1 \equiv \mathrm{N} 1 \bullet \bullet$ and $\bullet \bullet \mathrm{Se} 2-\mathrm{C} 2 \equiv \mathrm{N} 2 \cdots \bullet \mathrm{Se} 2-\mathrm{C} 2 \equiv \mathrm{N} 2 \cdots \bullet$ running along the $a$ direction 
(Fig 8a). The third selenocyanate group connects those chains along $b$ through a weaker $\bullet \bullet S e 3-$ $\mathrm{C} 3 \equiv \mathrm{N} 3 \bullet \bullet \operatorname{Se} 3-\mathrm{C} 3 \equiv \mathrm{N} 3 \bullet \bullet$ chalcogen bond.

Table 2 Structural characteristics of chalcogen bonds in the crystal structures of $\mathbf{1 a}, \mathbf{1} \mathbf{b}, \mathbf{1} \mathbf{b} \cdot(\mathrm{DMF})$ and 2.

\begin{tabular}{|c|c|c|c|c|c|}
\hline Compound & \multicolumn{2}{|c|}{ Interaction } & Se•••Y $(\AA)$ & RR & $\mathrm{C}-\mathrm{Se} \bullet \bullet \bullet\left(^{\circ}\right)$ \\
\hline \\
\hline \multirow[t]{2}{*}{ intrachain } & Sel & $\mathrm{N} 1^{\mathrm{i}}$ & $3.023(5)$ & 0.876 & $168.5(2)$ \\
\hline & $\mathrm{Se} 2$ & $\mathrm{~N} 2^{\mathrm{i}}$ & $3.011(5)$ & 0.873 & $169.3(2)$ \\
\hline interchain & $\mathrm{Se} 3$ & $\mathrm{~N} 3^{\mathrm{ii}}$ & $3.243(8)$ & 0.941 & $134.8(2)$ \\
\hline \multicolumn{6}{|l|}{$1 b$} \\
\hline \multirow[t]{3}{*}{ intrachain } & Se1 & $\mathrm{N} 31^{\mathrm{iii}}$ & $2.986(18)$ & 0.865 & $171.4(4)$ \\
\hline & Se1 & $\mathrm{N} 32^{\mathrm{iii}}$ & $3.292(10)$ & 0.954 & $155.8(2)$ \\
\hline & $\mathrm{Se} 2$ & $\mathrm{~N} 1^{\mathrm{iv}}$ & $3.188(4)$ & 0.924 & $177.4(2)$ \\
\hline \multirow[t]{2}{*}{ interchain } & Se31 & $\mathrm{Se} 31^{\mathrm{v}}$ & $3.078(5)$ & 0.810 & $178.6(5)$ \\
\hline & Se32 & $\mathrm{N} 1^{\mathrm{vi}}$ & $3.336(6)$ & 0.967 & $155.8(3)$ \\
\hline \multicolumn{6}{|l|}{$\mathbf{1 b} \cdot(\mathrm{DMF})$} \\
\hline \multirow[t]{2}{*}{ intrachain } & $\mathrm{Se} 1$ & $\mathrm{~N} 1^{\mathrm{i}}$ & $2.960(4)$ & 0.858 & $175.4(1)$ \\
\hline & $\mathrm{Se} 2$ & $\mathrm{~N} 2^{\mathrm{i}}$ & $2.964(2)$ & 0.859 & $176.1(1)$ \\
\hline \multirow[t]{2}{*}{ with $D M F$} & $\mathrm{Se} 3$ & $\mathrm{~N} 3^{\mathrm{vii}}$ & $2.972(3)$ & 0.861 & $173.8(1)$ \\
\hline & Se1 & $\mathrm{O} 1^{\text {viii }}$ & $3.284(6)$ & 0.960 & $163.8(1)$ \\
\hline \multicolumn{6}{|l|}{2} \\
\hline intra layer & Se1 & $\mathrm{N} 1^{\mathrm{vii}}$ & $3.085(5)$ & 0.894 & $164.0(2)$ \\
\hline \multirow[t]{2}{*}{ inter layer } & Se1 & $\mathrm{N} 2^{\mathrm{viii}}$ & $3.202(20)$ & 0.928 & $167.6(2)$ \\
\hline & $\mathrm{Se} 2$ & $\mathrm{~N} 1^{\mathrm{ix}}$ & $3.370(14)$ & 0.977 & $170.0(2)$ \\
\hline
\end{tabular}



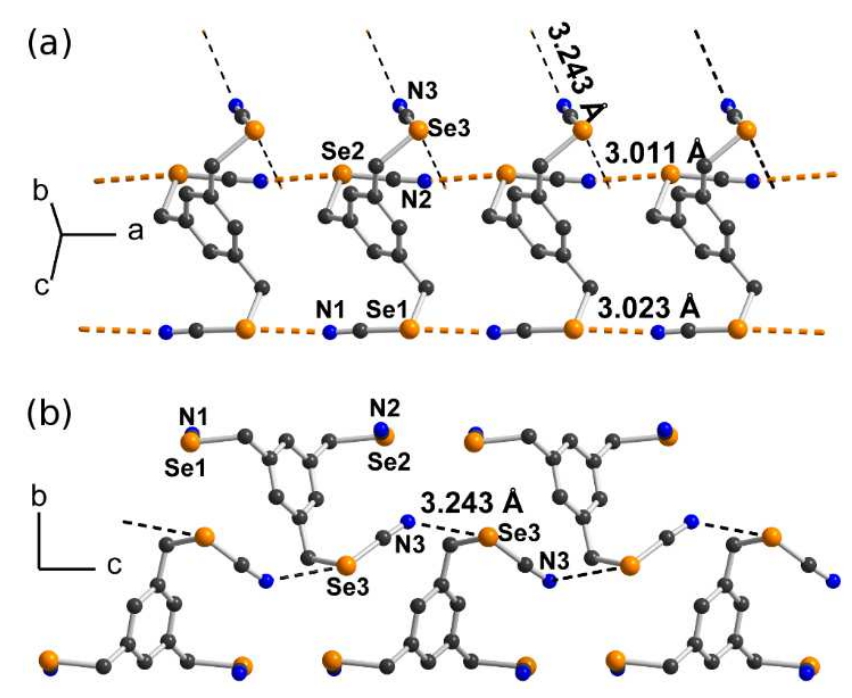

Fig. 8 Solid state organization of 1a showing (a) the chalcogen-bonded chains running along a, and (b) the lateral Se3 $\cdots$ N3 interactions.

The structure of $\mathbf{1 b}$ is more complex (Fig. 9). Two selenium atoms (Se1, Se2) interact with nitrogen atoms to generate a chain running along a $\left[\begin{array}{lll}1 & -1 & 0\end{array}\right]$ direction. A third disorder selenium atom (Se31) makes a very short Se•••Se contact with a neighboring chain running along the [1 $10]$ direction. As a consequence of this interchain Se•••Se interaction, one nitrogen atom (N2) is not engaged in a short contact.

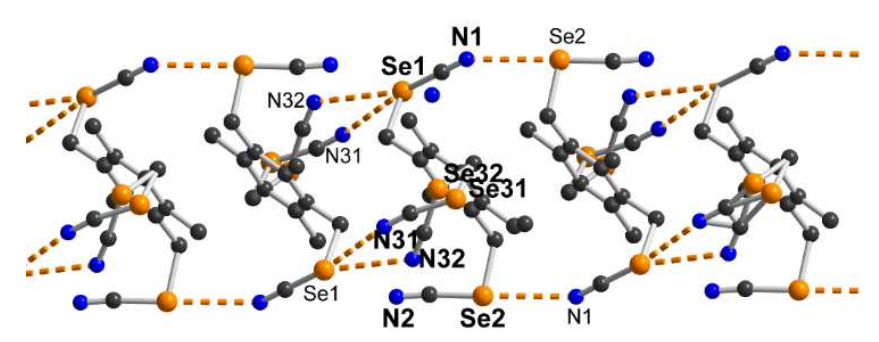

Fig. 9 Solid state organization of $1 \mathbf{b}$ showing the chalcogen-bonded chains running along $a$.

The structure of the DMF solvate of $\mathbf{1 b}$ is shown in Fig. 10 and it strongly differs from that of the pure compound. Indeed, the three selenocyanate groups are now engaged in short and directional Se $\bullet \bullet N$ interactions running parallel to each other to form a chain, while one of the selenium atoms also interacts weakly $(\mathrm{RR}=0.96)$ with the carbonyl oxygen atom of DMF. 


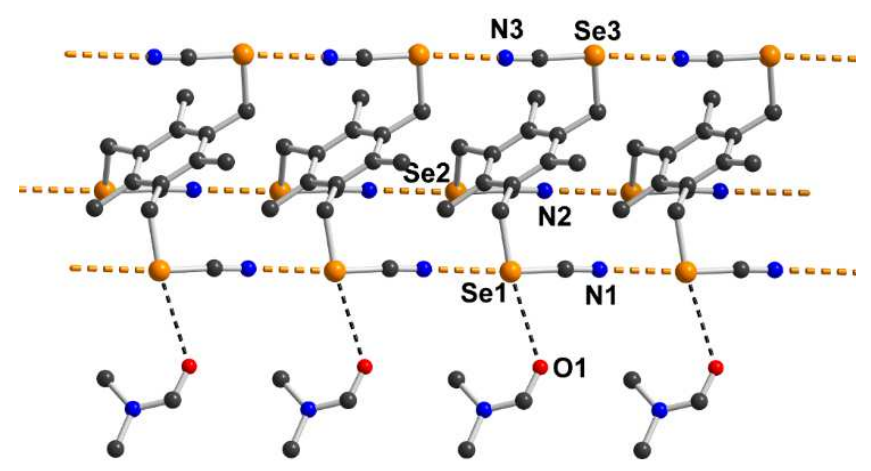

Fig. 10 Solid state organization of $1 \mathrm{~b} \cdot \mathrm{DMF}$

The structure of 2 (Fig. 11) is characterized by a strong Se1 $\bullet \bullet N 1$ interaction leading to the formation of layers. These layers are interconnected along $a$ through two weaker interactions, one involving again $\mathrm{Se} 1$ as chalcogen bond donor, the other involving Se2 (see Table 2).

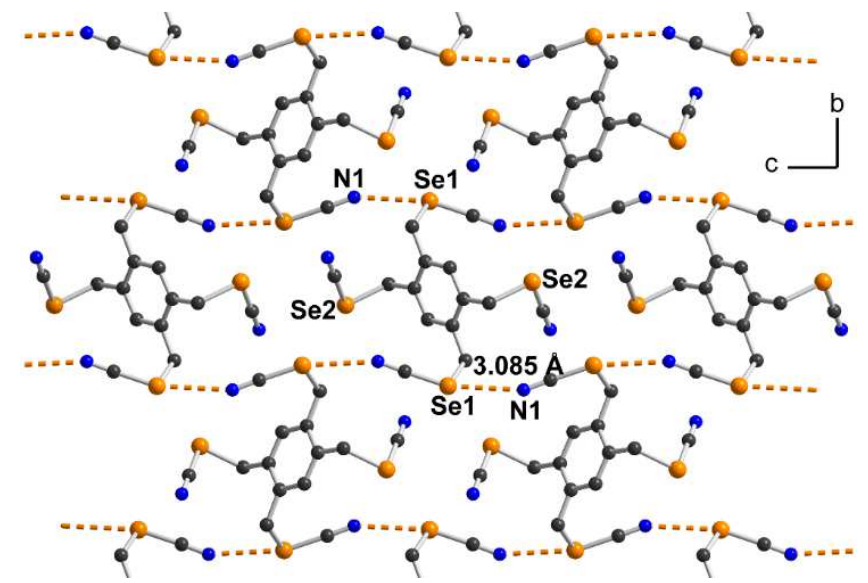

Fig. 11 Projection view along a of one layer in 2, built out the strongest Se1 $\cdots$ N1 chalcogen bond.

As mentioned above, both $\mathbf{1 b}$ and $\mathbf{2}$ were found to also co-crystallize with solvent molecules, affording two different solvates, namely $\mathbf{1 b \bullet A c O E t}$ and $\mathbf{2} \bullet(\mathrm{DMF})_{2}$. Their molecular structures are detailed in Fig. 12, their structural characteristics in Table 3.

In 1b•AcOEt, the AcOEt molecule is disordered on two equivalent (50:50) positions. In the solid state (Fig. 12a), the carbonyl oxygen atom competes now with the nitrile groups to engage in a chalcogen bond with one of the three selenium atoms of the $\mathbf{1 b}$ molecule. As a consequence, the infinite chain motifs observed above in the structure of 1b (Fig. 9) are now cut into a defined segment of three chalcogen bonds in the order (O11, O12)•••Se2- 
$\mathrm{C} \equiv \mathrm{N} 2 \cdot \bullet \mathrm{Se} 3-\mathrm{C} \equiv \mathrm{N} 3 \cdot \bullet \mathrm{Se} 1-\mathrm{C} \equiv \mathrm{N} 1$, with the $\mathrm{N} 1$ nitrogen atom not engaged in chalcogen bonding. The structure of the DMF solvate, $\mathbf{2} \bullet(\mathrm{DMF})_{2}$, reveals another facet of these benzylic selenocyanate derivatives. Indeed, as shown in Fig $11 \mathrm{~b}$, the molecule, located on inversion center, actually binds with the carbonyl oxygen atoms of the two DMF molecules, with two neighboring selenium atoms interacting with the same oxygen atom, providing a very attractive chelating system.

Table 3 Structural characteristics of chalcogen bonds in the crystal structures of the solvates $1 \mathbf{a}, \mathbf{1 b}, \mathbf{2}$

\begin{tabular}{|c|c|c|c|c|c|}
\hline \multirow{2}{*}{$\frac{\text { Compound }}{\mathbf{1 b} \cdot(\mathrm{AcOEt})}$} & \multicolumn{2}{|c|}{ Interaction } & \multirow{2}{*}{$\frac{\operatorname{Se} \bullet \bullet Y(\AA)}{3.174(4)}$} & \multirow{2}{*}{$\begin{array}{l}\text { RR } \\
0.92\end{array}$} & \multirow{2}{*}{$\frac{\left.\mathrm{C}-\mathrm{Se} \bullet \bullet Y{ }^{(}\right)}{177.0(1)}$} \\
\hline & Se1 & $\mathrm{N} 3^{\mathrm{i}}$ & & & \\
\hline & $\mathrm{Se} 2$ & $\mathrm{O} 11^{\mathrm{ii}}$ & $2.925(6)$ & 0.855 & $166.5(1)$ \\
\hline & $\mathrm{Se} 2$ & $\mathrm{O} 12^{\mathrm{ii}}$ & $2.871(7)$ & 0.839 & $168.8(2)$ \\
\hline & $\mathrm{Se} 3$ & $\mathrm{~N} 2^{\mathrm{iii}}$ & $2.965(3)$ & 0.859 & $174.9(1)$ \\
\hline \multirow[t]{2}{*}{$\mathbf{2} \cdot(\mathrm{DMF})_{2}$} & Se1 & $\mathrm{O} 1^{\mathrm{iv}}$ & $2.946(12)$ & 0.861 & $171.9(2)$ \\
\hline & $\mathrm{Se} 2$ & $\mathrm{O} 1^{\mathrm{iv}}$ & $2.937(49)$ & 0.859 & $175.2(2)$ \\
\hline
\end{tabular}

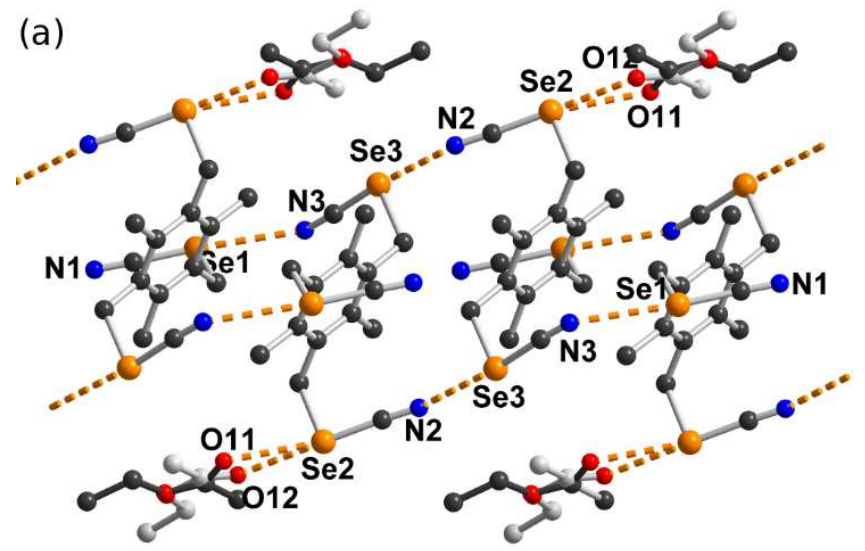

(b)

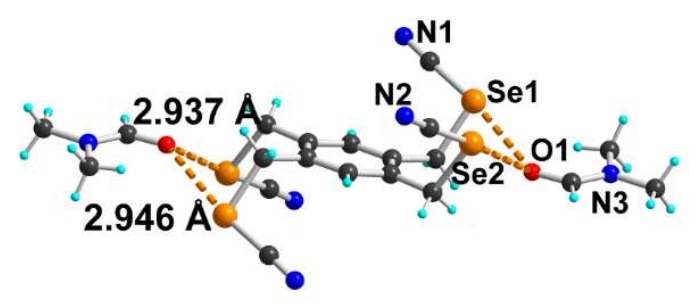

Fig. 12 Details of the supramolecular organization in (a) $\mathbf{1 b} \cdot A c O E t$, and (b) $\mathbf{2} \cdot(D M F)_{2}$. 


\section{Conclusions}

We have demonstrated here that organic selenocyanates provide a tutorial example of chalcogen bond donors. Compared with symmetrical selenides where experimental and theoretical evidences confirm the presence of two equivalent $\sigma$-holes located in the $\mathrm{C}-\mathrm{Se}-\mathrm{C}$ plane in the prolongation of the $\mathrm{C}-\mathrm{Se}$ bonds, the unsymmetrical character of $\mathrm{R}-\mathrm{Se}-\mathrm{CN}$ derivatives strongly favor the $\sigma$-hole in the prolongation of the NC-Se bond. Recurrent features are found from this extensive set of crystal structures based on organic selenocyanates. The most striking one is the formation of one-dimensional superstructures derived from the complementary nature of the $\mathrm{R}-\mathrm{SeCN}$ molecules, with the lone pair of the nitrogen interacting with the selenium $\sigma$-hole through a linear $\mathrm{C}-\mathrm{Se} \bullet \bullet \mathrm{NC}$ interaction and a reduction ration (RR) around $0.86-0.87$. This interaction is however relatively weak since it is displaced by pyridinyl nitrogen atom or with carbonyl (or nitro) oxygen atom, leading then to slightly stronger chalcogen bonds, with RR values down to 0.82 . The observed chain-like structures are also a probable consequence of an extra stabilization brought by cooperativity. Also, the structure of $2 \cdot(\mathrm{DMF})_{2}$ with two ortho $\mathrm{CH}_{2} \mathrm{SeCN}$ groups bonding to the carbonyl oxygen atom of the DMF (Fig. 12b) demonstrates that such ortho-substituted derivatives can adapt their geometry to act as chelating systems. Such ditopic or tritopic chelate structures have been recently considered in halogen bonded systems, ${ }^{31}$ either for anion recognition purposes ${ }^{32}$ or for catalytic applications. ${ }^{33}$ In these reported examples however, complex structural motifs have to be elaborated to orient two (or three) iodine atoms in a convergent interaction. The example of this selenocyanate derivative 2 in its DMF solvate demonstrates that such a goal can most probably be reached in much simpler molecules than these complex poly-iodinated ones. Work is also underway to test these assumptions.

\section{Experimental Section}

\section{Synthesis}

1,3,5-tris(bromomethyl)benzene, 1,3,5-tris(bromomethyl)-2,4,6-trimethylbenzene, 1,2,4,5tetrakis(bromomethyl)benzene were obtained from Aldrich or Across and used as received.

Synthesis of 1a. A solution of potassium selenocyanate $(0.32 \mathrm{~g}, 2.24 \mathrm{mmol}, 4$ equiv) in acetone $(5 \mathrm{~mL})$ is added dropwise over a period of 10 minutes on a solution of 1,3,5tris(bromomethyl)benzene $(0.2 \mathrm{~g}, 0.56 \mathrm{mmol}, 1$ equiv) in acetone $(5 \mathrm{~mL})$. The solution gets 
cloudy and a solid appear. The reaction is monitored by TLC (eluent petroleum ether/Ether 1/2). After completion of the reaction (typically 25 minutes), the mixture was filtered. The filtrate was evaporated under reduced pressure. The white solid was washed twice with $15 \mathrm{~mL}$ of warm water $\left(40^{\circ} \mathrm{C}\right)$ in ultrasonic bath during 5 minutes. The solid was filtered and dried overnight at $80^{\circ} \mathrm{C}$. M.p. $168{ }^{\circ} \mathrm{C}$, yield $45 \%$. ${ }^{1} \mathrm{H}$ NMR (300 MHz, d6-acetone) $\delta 7.51(\mathrm{~s}, 3 \mathrm{H})$, 4.48 (s, 6H). ${ }^{13} \mathrm{C}$ NMR (300 MHz, d6-acetone): $138.9(\mathrm{C}=\mathrm{C}), 129.3(=\mathrm{CH}), 102.1(\mathrm{CN}), 31.6$ $\left(\mathrm{CH}_{2}\right) .{ }^{77} \mathrm{Se}\left(\mathrm{d}_{6}-\mathrm{DMSO}, 25^{\circ} \mathrm{C}\right): 314.26 \mathrm{ppm}$ (3 Se, s). Elem. Anal. Calculated for $\mathrm{C}_{12} \mathrm{H}_{9} \mathrm{~N}_{3} \mathrm{Se}_{3}$ : C, 33.36; H, 2.10; N, $9.72 \%$. Found: C, 33.97; H, 2.46; N, 9.31\%.

Synthesis of $\mathbf{1 b}$. Synthesis of $\mathbf{1 b}$. Procedure adapted from Lari et al.. ${ }^{34} 1,3,5$-tris(bromomethyl)2,4,6-trimethylbenzene $(0.098 \mathrm{~g}, 0.25 \mathrm{mmol})$ was added to a $50 \mathrm{~mL}$ round bottom flask, dissolved in $20 \mathrm{~mL}$ of acetone, and purged with Ar for 10 minutes. Potassium selenocyanate (0.209 $\mathrm{g}, 1.503 \mathrm{mmol}$ ) was dissolved in acetone $(7 \mathrm{~mL})$. KSeCN solution was added dropwise and stirred for 1 hour under inert atmosphere. The reaction was filtered and condensed under vacuum to leave a crude off-white, beige powder. The crude powder was dissolved in the minimal amount of DMF, precipitated out with $\mathrm{H}_{2} \mathrm{O}$ and filtered to give a white powder that was recrystallized by vapor diffusion of ether into a solution of $\mathbf{1 b}$ in ethyl acetate, leaving clear, colorless crystals $(0.094 \mathrm{~g}, 81 \%)$. Using DMF instead of AcOEt afforded the DMF solvate. ${ }^{1} \mathrm{H}\left(300 \mathrm{MHz}, \mathrm{d}_{6}\right.$-acetone $\left.25^{\circ} \mathrm{C}\right): 8.6234-8.6114(6 \mathrm{H}, \mathrm{S}), 7.5059-74938(9 \mathrm{H}, \mathrm{s}) .{ }^{13} \mathrm{C}$ (300 MHz, d6-acetone, $\left.25^{\circ} \mathrm{C}\right): 138.8764,132.7166,102.1961,29.7677,17.0772 .{ }^{77} \mathrm{Se}\left(\mathrm{d}_{6}-\right.$ DMSO, $25^{\circ} \mathrm{C}$ ): 250.45 (3 Se, s). Elem. Anal. Calcd. for $\mathrm{C}_{15} \mathrm{H}_{15} \mathrm{~N}_{3} \mathrm{Se}_{3}$ : C, 37.99; H, 3.19; N, 8.86 \%. Found: C, 37.82; H, 3.34; N, 8.75\%.

Synthesis of 2. A solution of potassium selenocyanate $(0.38 \mathrm{~g}, 2.6 \mathrm{mmol}, 6$ equiv) in DMF (5 $\mathrm{mL}$ ) is added dropwise over a period of $10 \mathrm{~min}$ in a solution of 1,2,4,5tetrakis(bromomethyl)benzene $(0.2 \mathrm{~g}, 0.4 \mathrm{mmol}, 1$ equiv). An orange colour appears quickly and the solution gets cloudy. The reaction is monitored by TLC (eluent petroleum ether/Ether 1/2). After completion of the reaction (typically 25 minutes), addition of $15 \mathrm{~mL}$ of warm water $\left(40^{\circ} \mathrm{C}\right)$ precipitated a solid. The solid was washed twice with $15 \mathrm{~mL}$ of warm water $\left(40^{\circ} \mathrm{C}\right)$ in ultrasonic bath during 5 minutes. The solid was filtered and dried overnight at $80^{\circ} \mathrm{C}$. White solid, dec $\mathrm{T}>160^{\circ} \mathrm{C}$ (yield 94\%). Recrystallization was performed from $\mathrm{PhCN}$ by vapor diffusion of $\mathrm{Et}_{2} \mathrm{O}$. When DMF is used rather than $\mathrm{PhCN}$, a DMF solvate is obtained instead formulated as $\mathbf{2} \bullet(\mathrm{DMF})_{2} .{ }^{1} \mathrm{H} \mathrm{NMR}\left(300 \mathrm{MHz}, \mathrm{DMSO}-\mathrm{d}_{6}\right) \delta 7.38(\mathrm{~s}, 2 \mathrm{H}), 4.45(\mathrm{~s}, 8 \mathrm{H}) .{ }^{13} \mathrm{C} \mathrm{NMR}$ (300 MHz, DMSO-d $): 136.8(\mathrm{C}=\mathrm{C}), 133.8(=\mathrm{CH}), 104.9(\mathrm{CN}), 29.6\left(\mathrm{CH}_{2}\right) .{ }^{77} \mathrm{Se} \mathrm{NMR}\left(\mathrm{d}_{6}{ }^{-}\right.$ 
DMSO, $25^{\circ} \mathrm{C}$ ): 311.21 (4Se, s). Elem. Anal. Calcd. for $\mathrm{C}_{15} \mathrm{H}_{15} \mathrm{~N}_{3} \mathrm{Se}_{3} \mathrm{C}, 30.57 ; \mathrm{H}, 1.83 ; \mathrm{N}, 10.19$ \%. Found: C, 31.31; H, 2.19; N, $9.82 \%$.

\section{Crystallography}

Data were collected on an APEXII, Bruker-AXS diffractometer at room temperature for $\mathbf{1 a}, \mathbf{1 b}$, 2, 2•DMF, and on D8 VENTURE Bruker AXS diffractometer at $150 \mathrm{~K}$ for $\mathbf{1 b} \cdot \mathrm{DMF}$ and 1b•EtOAc. Both diffractometers operate with graphite-monochromated Mo-K $\alpha$ radiation $(\lambda=$

$0.71073 \AA$ ). The structures were solved by direct methods using the SIR92 program, ${ }^{35}$ and then refined with full-matrix least-square methods based on $F^{2}$ (SHELXL-2014/7) ${ }^{36}$ with the aid of the WINGX program. ${ }^{37}$ All non-hydrogen atoms were refined with anisotropic atomic displacement parameters. $\mathrm{H}$ atoms were finally included in their calculated positions. Crystallographic data on X-ray data collection and structure refinements are given in Table 4. CCDC 1820888-1820893 contains the supplementary crystallographic data for this paper. The data can be obtained free of charge from The Cambridge Crystallographic Data Centre via www.ccdc.cam.ac.uk/structures.

\section{Conflicts of interest}

There are no conflicts to declare.

\section{Acknowledgements}

Financial supports from (i) ANR (Paris, France) through contract ANR-17-CE07-0025-02, (ii) Rennes Métropole (Decision A17.612) and (iii) the Chateaubriand Fellowship of the Office for Science \& Technology of the Embassy of France in the United States are acknowledged. We also thank CDIFX (Rennes) for access to X-ray diffraction facilities and C. Orione (Scanmat Rennes) for the ${ }^{77} \mathrm{Se}$ NMR experiments. 
Table 4 Crystallographic data.

\begin{tabular}{|c|c|c|c|c|c|c|}
\hline & 1a & $1 \mathrm{~b}$ & $\mathbf{1 b} \cdot \mathrm{DMF}$ & $\mathbf{1 b} \cdot \mathrm{EtOAc}$ & 2 & $\mathbf{2 \bullet}(\mathrm{DMF})_{2}$ \\
\hline $\mathrm{CCDC}$ & 1820888 & 1820891 & 1820889 & 1820890 & 1820892 & 1820893 \\
\hline Formula & $\mathrm{C}_{12} \mathrm{H}_{9} \mathrm{~N}_{3} \mathrm{Se}_{3}$ & $\mathrm{C}_{15} \mathrm{H}_{15} \mathrm{~N}_{3} \mathrm{Se}_{3}$ & $\mathrm{C}_{18} \mathrm{H}_{22} \mathrm{~N}_{4} \mathrm{OSe}_{3}$ & $\mathrm{C}_{19} \mathrm{H}_{23} \mathrm{~N}_{3} \mathrm{O}_{2} \mathrm{Se}_{3}$ & $\mathrm{C}_{14} \mathrm{H}_{10} \mathrm{~N}_{4} \mathrm{Se}_{4}$ & $\mathrm{C}_{20} \mathrm{H}_{24} \mathrm{~N}_{6} \mathrm{O}_{2} \mathrm{Se}_{4}$ \\
\hline Formula moiety & $\mathrm{C}_{12} \mathrm{H}_{9} \mathrm{~N}_{3} \mathrm{Se}_{3}$ & $\mathrm{C}_{15} \mathrm{H}_{15} \mathrm{~N}_{3} \mathrm{Se}_{3}$ & $\begin{array}{l}\mathrm{C}_{15} \mathrm{H}_{15} \mathrm{~N}_{3} \mathrm{Se}_{3}, \\
\mathrm{C}_{3} \mathrm{H}_{7} \mathrm{NO}\end{array}$ & $\begin{array}{l}\mathrm{C}_{15} \mathrm{H}_{15} \mathrm{~N}_{3} \mathrm{Se}_{3}, \\
\mathrm{C}_{4} \mathrm{H}_{8} \mathrm{O}_{2}\end{array}$ & $\mathrm{C}_{14} \mathrm{H}_{10} \mathrm{~N}_{4} \mathrm{Se}_{4}$ & $\begin{array}{l}\mathrm{C}_{14} \mathrm{H}_{10} \mathrm{~N}_{4} \mathrm{Se}_{4} \\
2\left(\mathrm{C}_{3} \mathrm{H}_{7} \mathrm{NO}\right)\end{array}$ \\
\hline $\mathrm{FW}\left(\mathrm{g} \cdot \mathrm{mol}^{-1}\right)$ & 432.10 & 474.18 & 547.27 & 562.28 & 550.10 & 696.29 \\
\hline Space group & $\mathrm{P} 2{ }_{1} / \mathrm{n}$ & $\mathrm{C} 2 / \mathrm{c}$ & $\mathrm{P}-1$ & $\mathrm{C} 2 / \mathrm{c}$ & $\mathrm{P} 2{ }_{1} / \mathrm{c}$ & $\mathrm{P}-1$ \\
\hline a $(\AA)$ & $5.9630(2)$ & $18.8209(9)$ & $5.9559(5)$ & $18.5055(17)$ & $5.4173(12)$ & $9.224(5)$ \\
\hline $\mathrm{b}(\AA)$ & $23.1856(8)$ & $10.1135(5)$ & $10.0181(8)$ & $10.3314(9)$ & $13.172(3)$ & $9.382(5)$ \\
\hline c $(\AA)$ & $10.0548(4)$ & $17.9834(7)$ & $17.6631(13)$ & $23.327(2)$ & $11.795(2)$ & $9.591(5)$ \\
\hline$V\left(\AA^{3}\right)$ & 1388.17(9) & $3380.5(3)$ & $1024.47(14)$ & $4252.2(7)$ & $834.5(3)$ & $642.3(6)$ \\
\hline $\mathrm{T}(\mathrm{K})$ & $296(2)$ & $296(2)$ & $150(2)$ & $150(2)$ & $296(2)$ & 296(2) \\
\hline $\mathrm{Z}$ & 4 & 8 & 2 & 8 & 2 & 1 \\
\hline $\mathrm{D}_{\text {calc }}\left(\mathrm{g} \cdot \mathrm{cm}^{-1}\right)$ & 2.068 & 1.863 & 1.774 & 1.757 & 2.189 & 1.800 \\
\hline$\mu\left(\mathrm{mm}^{-1}\right)$ & 7.933 & 6.525 & 5.400 & 5.209 & 8.792 & 5.74 \\
\hline Total refls & 9778 & 15377 & 31696 & 48703 & 6327 & 14597 \\
\hline$\theta_{\max }\left({ }^{\circ}\right)$ & 27.491 & 27.491 & 27.505 & 27.553 & 27.638 & 27.506 \\
\hline \multicolumn{7}{|l|}{$(\mathrm{I}>2 \sigma(\mathrm{I}))$} \\
\hline $\mathrm{R}_{1}$ & 0.0513 & 0.0381 & 0.0316 & 0.0342 & 0.0439 & 0.040 \\
\hline $\mathrm{wR}_{2}$ (all data) & 0.1066 & 0.0991 & 0.0706 & 0.0816 & 0.1185 & 0.0906 \\
\hline GOF & 1.097 & 0.891 & 1.198 & 1.06 & 0.914 & 1.118 \\
\hline Res. dens. $\left(\mathrm{e} \AA^{-3}\right.$ ) & $0.765,-0.727$ & $0.505,-0.636$ & $0.865,-1.3$ & $0.535,-1.471$ & $0.745,-0.632$ & $0.891,-0.941$ \\
\hline
\end{tabular}




\section{References}

1 (a) G. Cavallo, P. Metrangolo, R. Milani, T. Pilati, A. Priimagi, G. Resnati and G. Terraneo, Chem. Rev., 2016, 116, 2478-2601; (b) L. C. Gilday, S. W. Robinson, T. A. Barendt, M. J. Langton, B. R. Mullaney and P. D. Beer, Chem. Rev., 2015, 115, 7118 7195.

2 (a) P. Politzer and J. S. Murray, ChemPhysChem, 2013, 14, 278-294; (b) P. Politzer, J. S. Murray and T. Clark, Phys. Chem. Chem. Phys., 2013, 15, 11178-11189; (c) P. Politzer, K. E. Riley, F. A. Bulat and J. S. Murray, Comput. Theor. Chem., 2012, 998, 2-8; (d) P. Politzer, J. S. Murray and J. S. Concha, J. Mol. Model., 2008, 14, 659-665.

3 (a) A. Bauza, D. Quinonero, P. M. Deya and A. Frontera, CrystEngComm, 2013, 15, 31373144, (b) D. J. Pascoe, K. B. Lin, and S. L. Cockroft, J. Am. Chem. Soc., 2017, 139, 15160-15167; (c) E. Alikhani, F. Fuster, B. Madebene and S. J. Grabowski, Phys. Chem. Chem. Phys., 2014, 16, 2430-2442.

4 A. F. Cozzolino, P. J. W. Elder and I. Vargas-Baca, Coord. Chem. Rev., 2011, 255, 14261438.

5 A. Kremer, A. Fermi, N. Biot, J. Wouters and D. Bonifazi, Chem. - Eur. J., 2016, 22, $5665-5675$.

${ }^{6}$ P. C. Ho, P. Szydlowski, J. Sinclair, P. J. W. Elder, J. Kubel, C. Gendy, L. M. Lee, H. Jenkins, J. F. Britten, D. R. Morim and I. Vargas-Baca, Nat. Commun., 2016, 7, 1129911309.

${ }^{7}$ M. Brezgunova, J. Lieffrig, E. Aubert, S. Dahaoui, P. Fertey, S. Lebègue, J. Angyan, M. Fourmigué and E. Espinosa, Cryst. Growth Design 2013, 13, 3283-3289

${ }^{8}$ S. Benz, J. Lopez-Andarias, J. Mareda, N. Sakai, S. Matile, Angew. Chem. Int. Ed. 2017, $56,812-815$;

${ }^{9}$ P. Wonner, L. Vogel, M. Düser, L. Gomes, F. Kniep, B. Mallick, D. B. Werz, and S. M. Huber, Angew. Chem. Int. Ed., 2017, 56, 12009-12012.

${ }^{10}$ Y. Geboes, F. De Vleeschouwer, F. De Proft and W. A. Herrebout, Chem. Eur. J., 2017, 23, 17384-17392.

11 K. H. Linke and F. Lemmer, Z. Anorg. Allg. Chem., 1966, 345, 211-216.

12 T. M. Klapötke, B. Krumm and M. Scherr, Inorg. Chem., 2008, 47, 7025-7028

13 S. Fritz, C. Ehm and D. Lentz, Inorg. Chem., 2015, 54, 5220-5231.

14 Cambridge Structural Database, Version 5.38, Nov. 2016.

15 H.-T. Huynh, O. Jeannin and M. Fourmigué, Chem. Commun., 2017, 53, 8467-8469 
${ }^{16}$ P. G. Jones, C. Wismach, G. Mugesh and W.-W. du Mont, Acta Cryst., 2002, E58, o1298o1300.

${ }^{17}$ K. Maartmann-Moe, G. O. Nevstad and J. Songstad, Acta Chem. Scand. A, 1986, 40, 182189.

${ }^{18}$ P. Rakesh, H. B. Singh and R. J. Butcher, Organometallics, 2013, 32, 7275-7282.

${ }^{19}$ N. A. Barnes, S. M. Godfrey, R. T. A. Halton, I. Mushtaq, S. Parsons, R. G. Pritchard and M. Sadler, Polyhedron, 2007, 26, 1053-1060.

${ }^{20}$ T. M. Klapötke, B. Krumm and K. Polborn, Eur. J. Inorg. Chem., 1999, 1359-1366.

${ }^{21}$ W. S. McDonald and L. D. Pettit, J. Chem. Soc. A, 1970, 2044-2046.

${ }^{22}$ T. M. Klapotke, B. Krumm, P. Mayer, H. Piotrowski and M. Vogt, Z. Anorg. Allg. Chem., 2003, 629, 1117-1123.

${ }^{23}$ J. George, V. L. Deringer, and R. Dronskowski, J. Phys. Chem. A, 2014, 118, 3193-3200.

${ }^{24}$ S. J. Dunne, L. A. Summers, E. I. von Nagy-Felsobuki and M. F. Mackay, Acta Cryst. C, 1994, 50, 971-974.

${ }^{25}$ K. Maartmann-Moe, K. A. Sanderud and J. Songstad, Acta Chem. Scand. A, 1984, 38, $187-$ 200.

${ }^{26}$ S. L. W. McWhinnie, A. B. Brooks and I. Abrahams, Acta Cryst. C, 1998, 54, 126-128.

${ }^{27}$ A. Lari, R. Gleiter and F. Rominger, Eur. J. Org. Chem., 2009, 2267-2274.

${ }^{28}$ A. Lari, C. Bleiholder, F. Rominger and R. Gleiter, Eur. J. Org. Chem., 2009, 2765-2774.

${ }^{29}$ D. B. Werz, F. R. Fischer, S. C. Kornmayer, F. Rominger and R. Gleiter, J. Org. Chem., 2008, 73, 8021-8029.

${ }^{30}$ R. Luboradzki, CSD Priv. Commun. 2015 (ZUTTAL)

${ }^{31}$ For a recent review, see: U. S. Schubert and R. Tepper, Angew. Chem. Int. Ed. 2018, DOI:10.1002/anie.201707986

${ }^{32}$ S. Scheiner, Chem. Eur. J., 2016, 22, 18850-18858

33 (a) D. Bulfield and S. M. Huber, Chem. Eur. J., 2016, 22 , 14434-14450; (b) S. H. Jungbauer, S. M. Walter, S. Schindler, L. Rout, F. Kniep and S. M. Huber, Chem. Commun., 2014, 50, 6281-6284; (c) F. Kniep, S. H. Jungbauer, Q. Zhang, S. M. Walter, S. Schindler, I. Schnapperelle, E. Herdtweck and S. M. Huber, Angew. Chem. Int. Ed., 2013, 52, 7028-7032; (d) Y. Takeda, D. Hisakuni, C. H. Lin and S. Minakata, Org. Lett., 2015, $17,318-321$.

${ }^{34}$ A. Lari, R. Gleiter and F. Rominger, Eur. J. Org. Chem., 2009, 2267-2274

${ }^{35}$ A. Altomare, G. Cascarano, C. Giacovazzo, A. Guagliardi, M. C. Burla, G. Polidori, M. Camalli, J. Appl. Cryst. 1994, 27, 435-436. 
${ }^{36}$ G. M. Sheldrick, Acta Cryst. C, 2015, 71, 3-8.

${ }^{37}$ L. J. Farrugia, J. Appl. Cryst., 2012, 45, 849-854. 


\section{For Table of Content}

Organic selenocyanates form recurrent chain-like motifs $\cdots \cdot \mathrm{Se}(\mathrm{R})-\mathrm{CN} \bullet \bullet \mathrm{Se}(\mathrm{R})-\mathrm{CN} \bullet \bullet$ through short and linear chalcogen bonding Se $\bullet \bullet N \equiv C$ interactions. A chelating motif is also observed in a DMF solvate with two neighboring $\mathrm{CH}_{2}-\mathrm{SeCN}$ groups linked to the DMF oxygen atom.

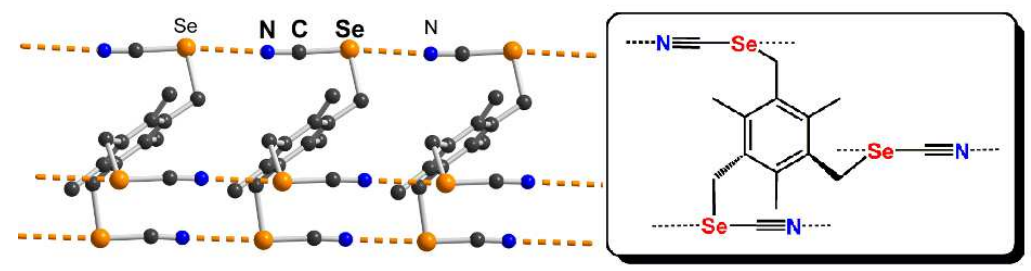

